\title{
Association of 5-alpha-reductase inhibitor and prostate cancer incidence and mortality: a meta-analysis
}

\author{
Xu Hu ${ }^{1 \#}$, Yao-Hui Wang ${ }^{1 \#}$, Zhi-Qiang Yang ${ }^{1 \#}$, Yan-Xiang Shao ${ }^{1}$, Wei-Xiao Yang ${ }^{1}$, Xiang Li $^{2}$ \\ ${ }^{1}$ West China School of Medicine/West China Hospital, Sichuan University, Chengdu, China; ${ }^{2}$ Department of Urology, West China Hospital, West \\ China Medical School, Sichuan University, Chengdu, China \\ Contributions: (I) Conception and design: X Li, X Hu; (II) Administrative support: None; (III) Provision of study materials: X Li; (IV) Collection and \\ assembly of data: X Hu, ZQ Yang, YH Wang, YX Shao; (V) Data analysis and interpretation: X Hu, YH Wang, WX Yang; (VI) Manuscript writing: \\ All authors; (VII) Final approval of manuscript: All authors. \\ "These authors contributed equally to this work. \\ Correspondence to: Prof. Xiang Li. Department of Urology, West China Hospital, West China Medical School, Sichuan University, 37 Guoxue Street, \\ Chengdu 610041, China. Email: hx_uro@sina.com.
}

Background: 5-Alpha-reductase inhibitors (5-ARIs) have been suggested as potential chemopreventive agents for prostate cancer (PCa). This study was conducted to evaluate the effect of 5-ARIs on the incidence and mortality of PCa.

Methods: The PubMed, Embase and Cochrane Library databases were searched comprehensively from database inception to October 2019. The clinical outcomes included the incidence of overall PCa, highgrade (Gleason8-10) PCa, metastatic PCa, overall survival (OS), and cancer-specific survival (CSS).

Results: Overall, 23 studies were included in the present study, representing 11 cohort studies, 5 casecontrol studies, and 8 randomized controlled trials. The use of 5-ARIs was associated with a decreased risk of overall PCa [relative risk $(\mathrm{RR})=0.77 ; 95 \% \mathrm{CI}$ : 0.67-0.88; $\mathrm{P}<0.001$ ] and increased risk of Gleason 8-10 PCa $(\mathrm{RR}=1.19 ; 95 \% \mathrm{CI}: 1.01-1.40 ; \mathrm{P}=0.036)$. In terms of metastatic PCa, there were no significant betweengroup differences ( $\mathrm{RR}=1.23$; 95\% CI: 0.69-2.18; $\mathrm{P}=0.487$ ). Furthermore, we found that prediagnostic 5-ARI usage was not associated with an increased risk of overall or prostate cancer mortality, with HRs of 1.00 (95\% CI: $0.92-1.08 ; \mathrm{P}=0.938$ ) and 0.98 (95\% CI: 0.80-1.21; $\mathrm{P}=0.881$ ), respectively.

Conclusions: In conclusion, while male 5-ARI users were associated with a decreased risk of overall prostate cancer and increased risk of high-grade prostate cancer (Gleason 8-10), they were not associated with an increased risk of overall or prostate cancer mortality. 5-ARIs should be recommended carefully for use as chemopreventive agents.

Keywords: 5-alpha-reductase inhibitor; prostate cancer (PCa); incidence; mortality; meta-analysis

Submitted Apr 01, 2020. Accepted for publication Sep 11, 2020.

doi: $10.21037 /$ tau-20-843

View this article at: http://dx.doi.org/10.21037/tau-20-843

\section{Introduction}

Prostate cancer ( $\mathrm{PCa}$ ) is the second most commonly diagnosed noncutaneous malignancy and the fifth leading cause of cancer mortality in men worldwide (1), and mortality from PCa $(359,000$ deaths in 2018) is markedly lower than PCa incidence (1.3 million new cases in 2018) (1). Due to the high occurrence of prostate cancer as well as the human and economic cost of treatment, preventive measures would have a powerful impact on public health (2). In addition, PCa could be an ideal target for chemoprevention because of its attributes, such as long latency period and multistep pathogenesis (3).

5 -alpha reductase inhibitors (5-ARIs), such as finasteride and dutasteride, are commonly used in the treatment of benign prostatic hyperplasia (BPH). They inhibit the conversion of testosterone to the more potent 
dihydrotestosterone, which reduces the prostate volume and improves urinary flow obstruction (4). 5-ARIs have been suggested as potential chemopreventive agents for prostate cancer.

Two large randomized controlled trials (RCTs), the Prostate Cancer Prevention Trial (PCPT) and Reduction by Dutasteride of Prostate Cancer Events (REDUCE), showed $24.8 \%$ and $22.8 \%$ risk reductions in prostate cancer incidence with the use of 5 -ARIs, respectively $(5,6)$. However, both trials observed that 5-ARI users have an unexpected increased risk of high-grade tumors compared with placebo $(5,6)$. Because it remains unknown whether the association was a result of bias, the utilization of 5-ARIs for chemoprevention is not endorsed.

It can be hypothesized that, because 5-ARIs increase the risk of high-grade tumors, they should increase the risk of prostate cancer outcomes, such as mortality. To date, several contradictory studies have explored the impact of 5-ARIs on prostate cancer outcomes (7-10). In addition, some studies did not detect an association between the use of 5 -ARIs and increased risk of high-grade tumor $(2,11)$. As a result, we performed the present study and summarized all relevant studies to evaluate the association between 5-alphareductase inhibitors and prostate cancer incidence and mortality. We present the current study in accordance with the Preferred Reporting Items for Systematic Reviews and Meta-Analyses (PRISMA) reporting checklist (12) (available at http://dx.doi.org/10.21037/tau-20-843).

\section{Methods}

\section{Literature search strategy}

PubMed, Cochrane Library, and Embase were comprehensively searched from inception to October 2019. We adopted the following search items: 5 -alpha reductase inhibitor (5-a-reductase inhibitor, 5-ARIs, finasteride, dutasteride, epristeride) and prostate cancer. We also reviewed reference lists of eligible studies to identify any additional relevant studies. Two investigators conducted the literature search independently, and any disagreement was resolved by consulting a third investigator.

\section{Inclusion and exclusion criteria}

We included studies that met the following criteria: (I) population-based studies; (II) 5-ARIs were used before the diagnosis of $\mathrm{PCa}$; (III) compared 5-ARI users with placebo or nonusers; (IV) reported clinical outcomes, such as prostate cancer incidence, mortality, or recurrence. We removed the following studies: (I) non-English language; (II) 5-ARIs were used after the diagnosis or treatment of PCa; (III) did not report relevant clinical outcomes; (IV) reviews and conference abstracts. For duplicated records, we only enrolled the study with the largest cases and most applicable information.

\section{Data extraction and quality assessment}

Two investigators independently extracted the following information from each study: first author's name, published year, study design, enrollment data and location, disease, drugs in experimental and control groups, number of cases, age, clinical outcomes, and the duration of follow-up. We evaluated the quality assessment observation studies and RCTs using the Newcastle-Ottawa Quality Assessment Scale (NOS) and the Cochrane Collaboration Risk of Bias Tool, respectively (13).

\section{Statistical analysis}

For prostate cancer incidence, we used relative risk (RR) as the statistic. For the clinical outcomes, such as overall survival (OS) and cancer-specific survival (CSS), the hazard ratio (HR) was applied. The heterogeneity among studies was evaluated by calculating the $\mathrm{Q}$ and $\mathrm{I}^{2}$ statistics. If the $\mathrm{I}^{2}$ statistics showed $\mathrm{P}<0.10$ or $\mathrm{I}^{2}>50 \%$, a random-effect model was applied (14). Sensitivity analysis was carried out by repeating the meta-analysis after the removal of each study and assessing the robustness of the combined estimate. Concerning publication bias, we applied the Egger's test and Begg's test. If publication bias was detected, the trim and fill method was used to estimate the missing studies and recalculate the statistics (15). We also performed subgroup analysis and meta-regression to explore the potential source of heterogeneity. Statistical analyses were conducted using STATA version 12 (StataCorp, College Station, TX, USA). A two-sided $\mathrm{P}$ value $<0.05$ was regarded as statistically significant.

\section{Results}

\section{Study selection}

Our initial search strategy yielded 4,976 records, whose titles and abstracts were screened. After the removal of 


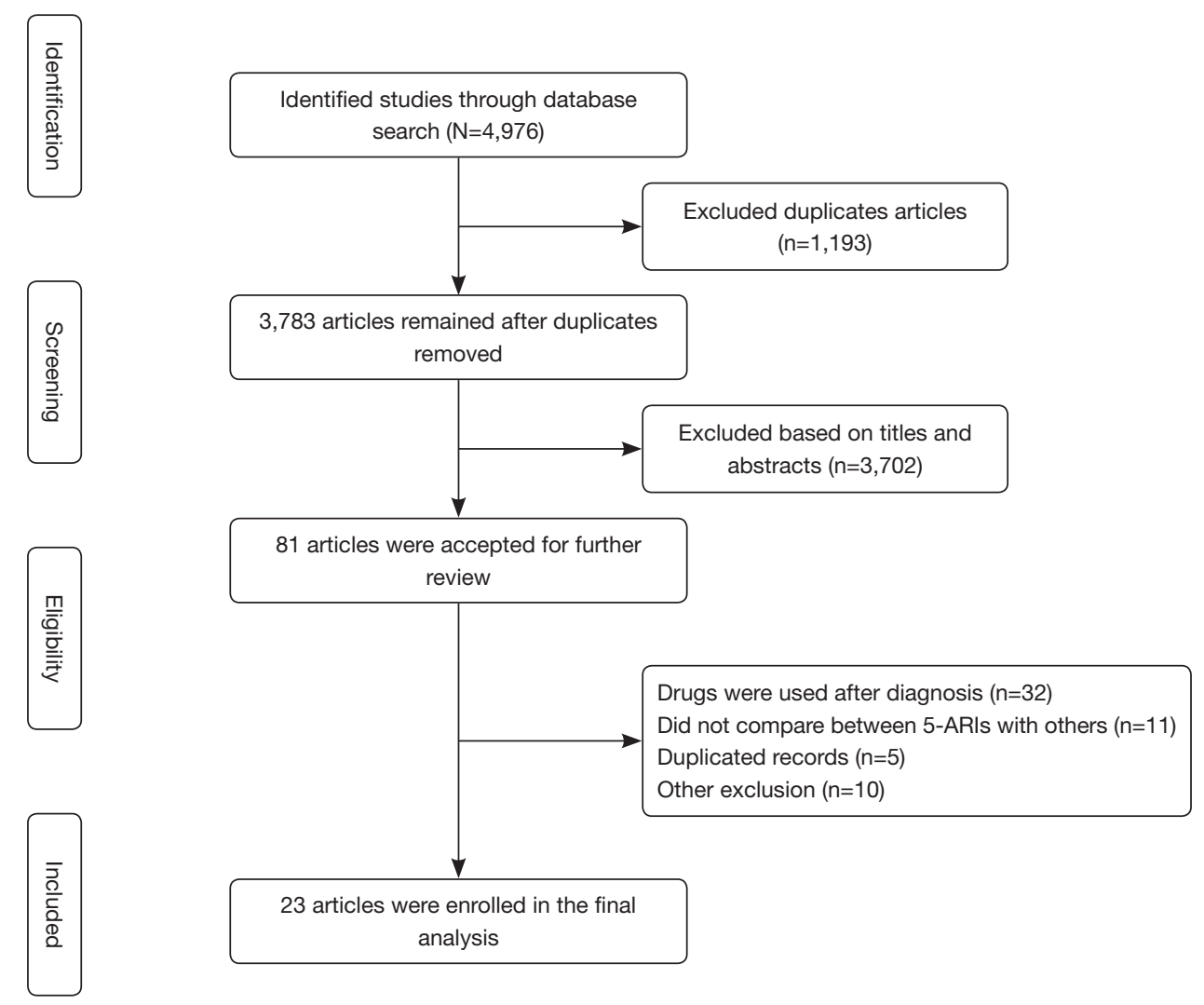

Figure 1 Flow chart of the study selection.

duplicated records and initial screening, 81 studies were further reviewed in the full text. At the end of the process, 23 studies were confirmed to match the eligibility criteria and enrolled in the final analysis (2,5-10,16-31) (Figure 1).

\section{Clinical characteristic of the enrolled studies}

Overall, 23 studies were included in the present study. They included men from the United States, France, Sweden, Finland, and others. Of the included studies, 11 were cohort studies, 5 were case-control studies, and 8 were RCTs. One study consisted of a cohort and case-control study (8). Men in the 5-ARI group used finasteride or dutasteride, and men in the control group used a-blockers, non-5-ARIs or placebo. The sample sizes of the enrolled studies were relatively large except for one RCT, which enrolled less than 200 men. Most studies included men older than 65 years. Of the reported studies, the duration of follow-up was long, ranging from 1 year to 18 years. For the observation studies, we used the NOS to evaluate the quality assessment, and all studies were considered high quality. The detailed information is summarized in Table 1 . The quality assessment of RCT is presented in Table S1.

\section{Overall prostate cancer}

Concerning the incidence of overall $\mathrm{PCa}, 16$ studies reported relevant information. We found that the use of 5-ARIs was associated with decreased risk of overall PCa, with an RR of 0.77 (95\% CI: 0.67-0.88; P<0.001; Figure $2 A)$. We detected significant heterogeneity $\left(\mathrm{I}^{2}=91.5 \% ; \mathrm{P}<0.001\right)$; thus, we used the random-effect model. When stratified by study design, we also observed a significant association between the use of 5-ARIs and decreased risk of overall $\mathrm{PCa}$ in the cohort study $(\mathrm{RR}=0.72$; $\mathrm{P}=0.046)$, case-control study $(\mathrm{RR}=0.87 ; \mathrm{P}=0.004)$ and $\mathrm{RCT}$ $(\mathrm{RR}=0.77 ; \mathrm{P}=0.001)$.

\section{Gleason 8-10 prostate cancer}

Fourteen studies revealed the incidence of Gleason 810 PCa. We observed that 5-ARI users had a significantly 


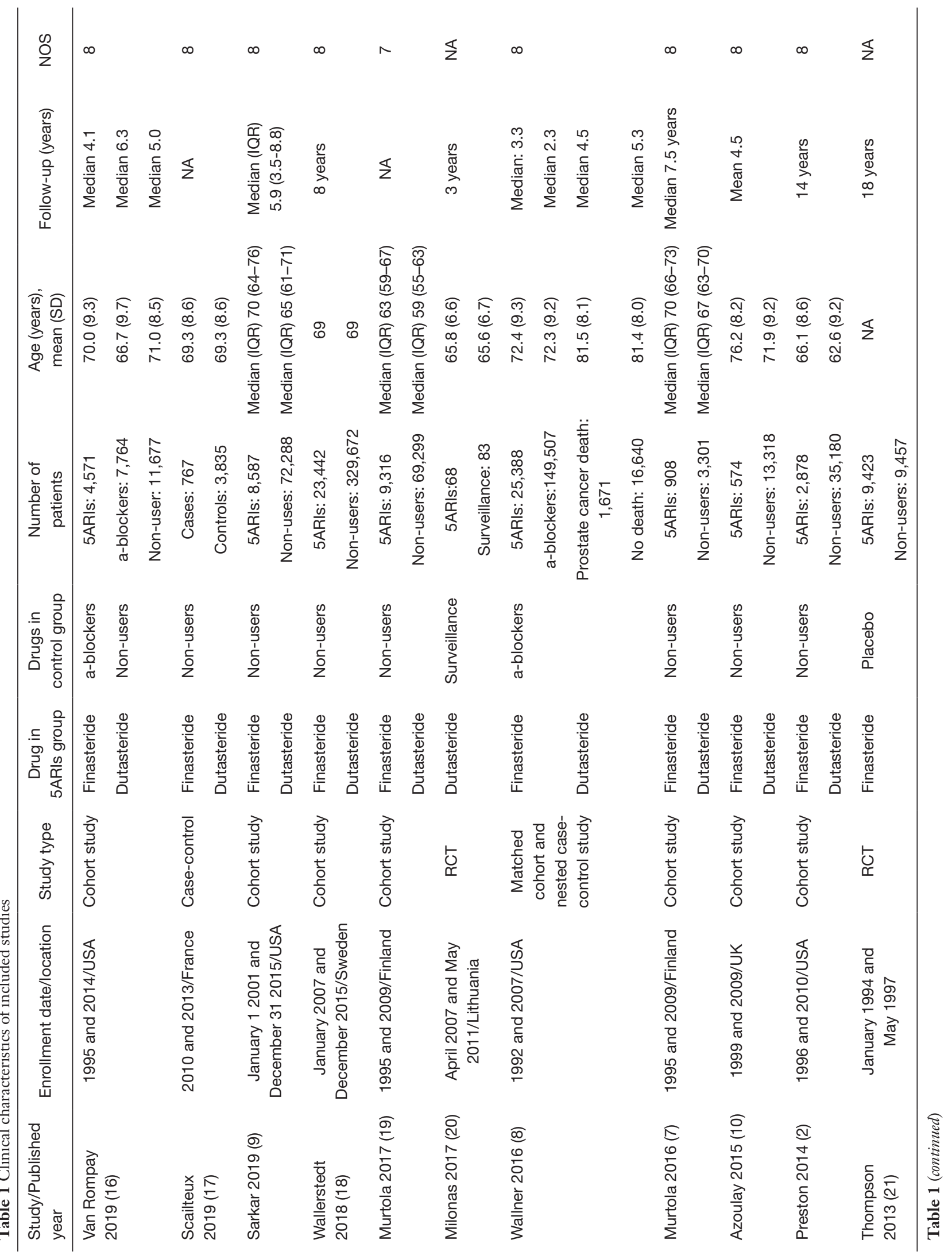




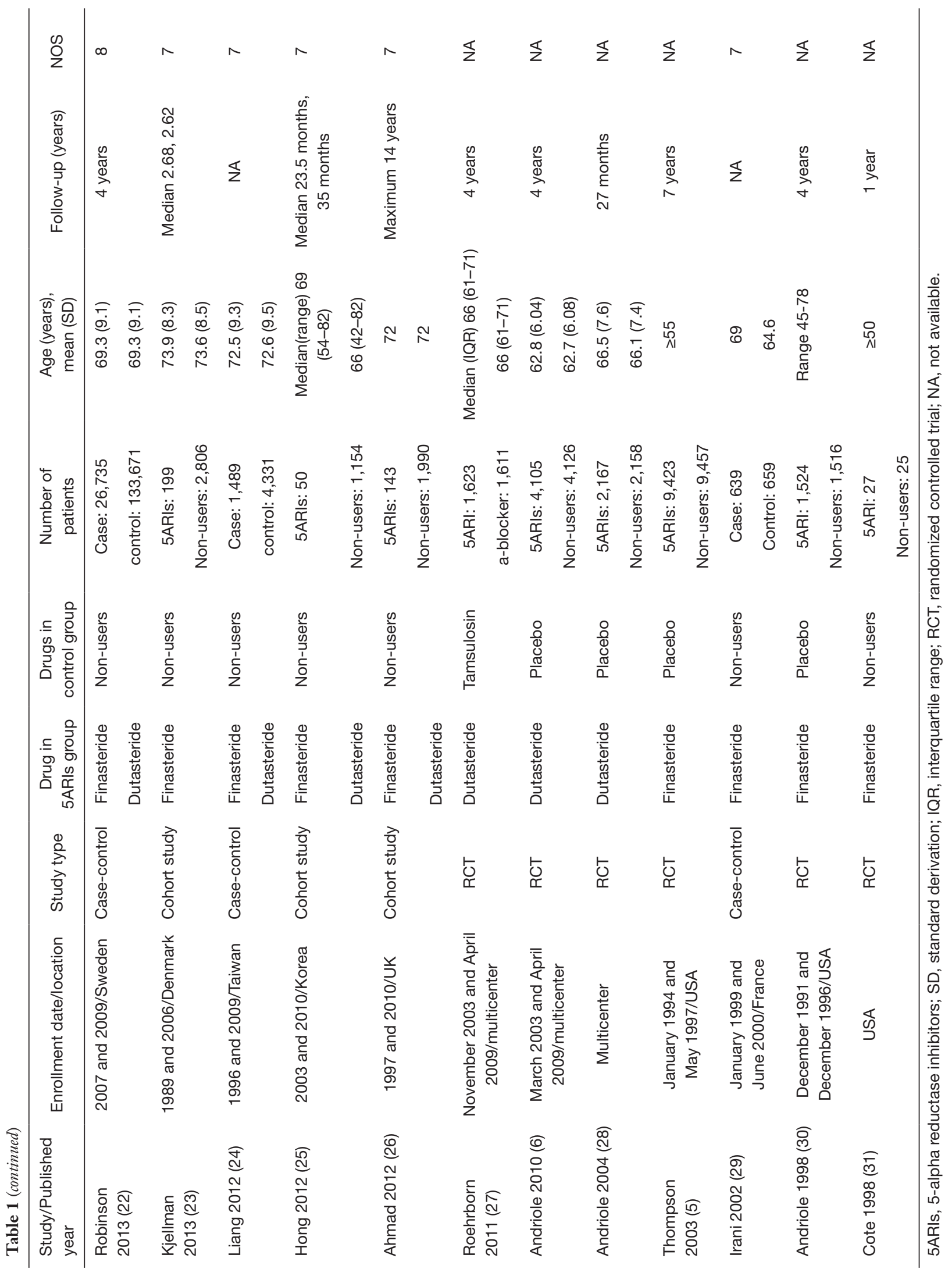


increased incidence of Gleason 8-10 PCa compared with nonusers, with an RR of 1.19 (95\% CI: 1.01-1.40; $\mathrm{P}=0.036$; Figure $2 B)$. Because of the heterogeneity $\left(\mathrm{I}^{2}=70.2 \%\right.$; $\mathrm{P}<0.001)$, the random-effect model was used. When stratified by study design, we found that 5 -ARI users had a comparable risk of incidence of Gleason 8-10 PCa in the cohort study ( $R R=1.2 ; \mathrm{P}=0.06$ ), case-control study ( $\mathrm{RR}$ $=1.02 ; \mathrm{P}=0.703)$ and $\mathrm{RCT}(\mathrm{RR}=1.17 ; \mathrm{P}=0.575)$.

\section{Metastatic prostate cancer}

Three cohort studies presented data describing the use of 5-ARIs and the incidence of metastatic PCa. There was significant heterogeneity among studies $\left(I^{2}=94.5 \%\right)$; thus, we used the random-effect model. We observed that the incidence of metastatic $\mathrm{PCa}$ was comparable between the two groups ( $R R=1.23 ; 95 \% \mathrm{CI}: 0.69-2.18 ; \mathrm{P}=0.487$; Figure 2C).

\section{Overall survival}

In terms of overall survival, 6 studies reported relevant information for analysis. There was no significant difference in OS between 5-ARIs and nonusers, with an HR of 1.00 (95\% CI: 0.92-1.08; $\mathrm{P}=0.938 ; \mathrm{I}^{2}=66.5 \%$; Figure $3 A$ ). Similarly, no significant differences in OS was found between the two groups in the subgroup of the cohort study and $\mathrm{RCT}(\mathrm{HR}=0.97, \mathrm{P}=0.632 ; \mathrm{HR}=1.03 ; \mathrm{P}=0.316$; respectively).

\section{Cancer-specific survival}

Regarding cancer-specific survival, 6 cohort studies evaluated the association between the 5-ARIs and CSS. As shown in Figure 3B, CSS was comparable between two groups, with an HR of 0.98 (95\% CI: $0.80-1.21 ; \mathrm{P}=0.881$; $\left.\mathrm{I}^{2}=86.5 \%\right)$.

\section{Sensitivity analysis and publication bias}

We carried out the sensitivity analyses by removing each study in sequence to identify the robustness of our results. We did not observe large changes, which indicates the stability of the final results (Figure 4). We evaluated the publication bias for overall PCa and Gleason 8-10 PCa, and we did not observe significant publication bias based on the Egger's test $(\mathrm{P}=0.169, \mathrm{P}=0.079$; respectively) and Begg's test $(\mathrm{P}=0.837, \mathrm{P}=0.488$; respectively).

\section{Meta-regression and subgroup analysis}

According to the number of included studies, we carried out the meta-regression and meta-analyses for overall and Gleason 8-10 PCa based on the available results. Subgroup analyses were conducted based on the study design (cohort, case-control, RCT), the drugs in the control group (non5-ARIs, a-blockers, and placebo), region (America, Europe, Asia, and multicenter), the duration of 5-ARI use (ever-use and long-term ( $>6$ months) use) and the number of patients $(<5,000$ and $\geq 5,000)$. In terms of overall $\mathrm{PCa}$, we did not detect factors that had a significant impact on overall PCa. Nearly all subsets consistently showed that 5-ARIs were significantly associated with a decreased risk of overall PCa, except the Asia subgroup, which included only one study. Furthermore, the meta-regression indicated that the RRs of Gleason 8-10 PCa differed significantly according to the use group. The detailed information is presented in Table 2 .

\section{Discussion}

The enzyme 5-alpha-reductase promotes the conversion of testosterone to the biologically potent form, dihydrotestosterone, which is important in prostate development and maintenance (32). 5-ARIs, including finasteride and dutasteride, inhibit the conversion of testosterone, leading to low intraprostatic levels of dihydrotestosterone and the subsequent induction of apoptosis $(33,34)$. 5-ARIs are also commonly used in old men who suffer from BPH. Reportedly, two large scale RCT showed that 5-ARIs could decrease the risk of overall $\mathrm{PCa}$, but they found that 5 -ARI users had an increased risk of high-grade $\mathrm{PCa}(5,6)$. Whether 5 -ARIs have an impact on the incidence of high-grade $\mathrm{PCa}$ and survival is controversial. Recently, several studies reported relevant outcomes. Therefore, we conducted the present study to evaluate the relationship between 5-ARIs and PCa incidence and mortality.

In the present study, we observed that 5-ARI usage was significantly associated with a decreased risk of overall PCa. In each subgroup, the results were similar. For high-grade $\mathrm{PCa}$, the 5-ARI users had a significantly higher incidence of Gleason 8-10 PCa. When stratified by different variables, there were no significant differences in some subgroups. Furthermore, we found that duration of use might be the source of heterogeneity through the meta-regression. Some users are ever using, which means irregular use and may affect the results. As a result, the association between 
A

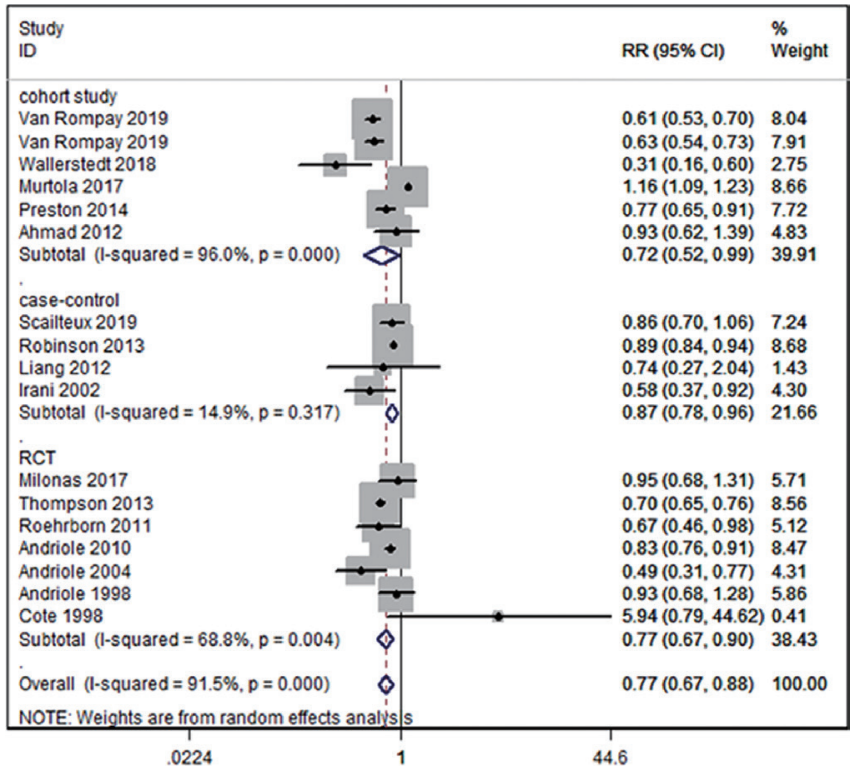

B
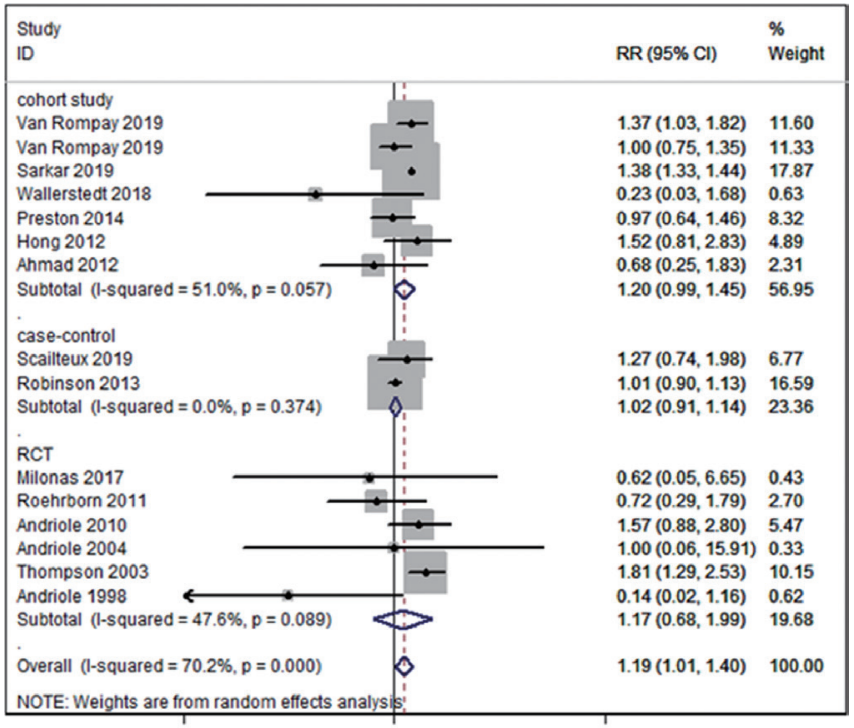

.02

50

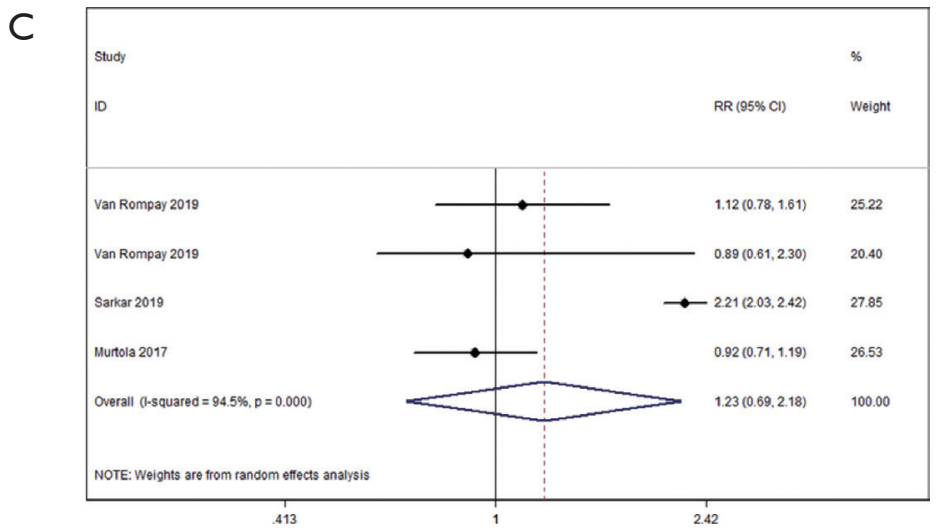

Figure 2 The association between 5-ARI use and the incidence of (A) overall prostate cancer; (B) Gleason 8-10 prostate cancer; (C) metastatic prostate cancer. 5-ARI, 5-alpha-reductase inhibitors. 

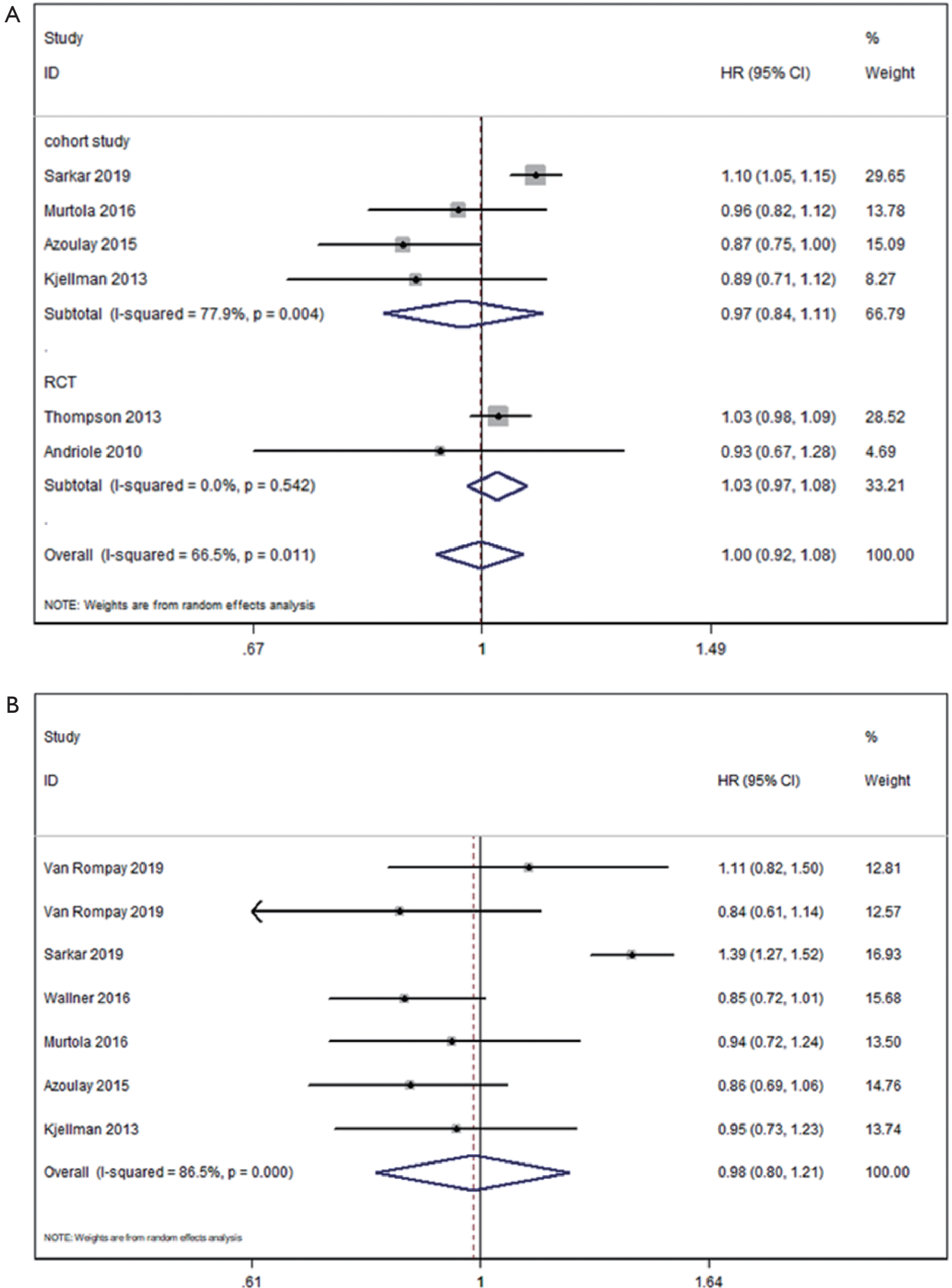

Figure 3 The association between 5-ARI use and (A) overall survival; (B) cancer-specific survival. 5-ARI, 5-alpha-reductase inhibitors. 
A

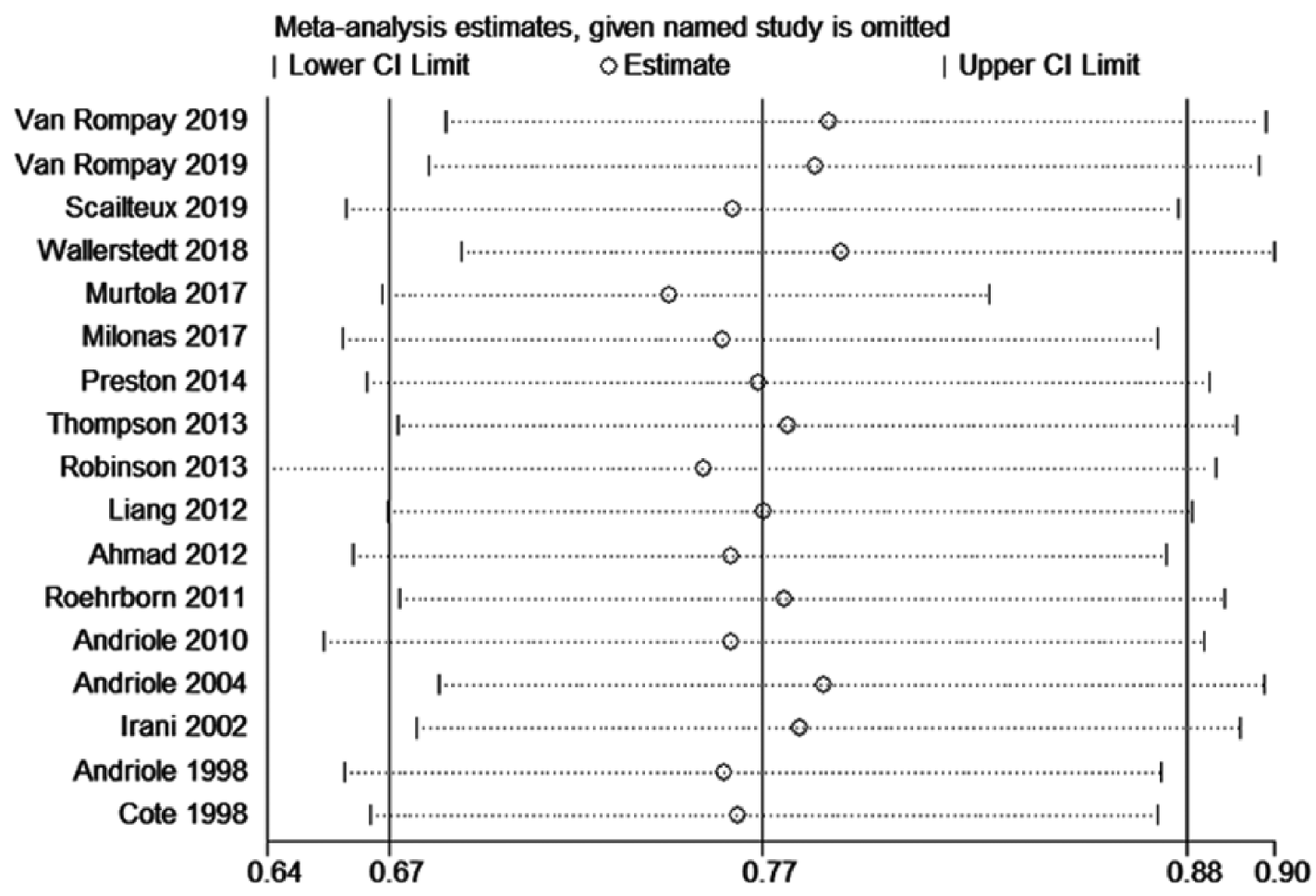

B

Meta-analysis estimates, given named study is omitted

\section{| Lower CI Limit}

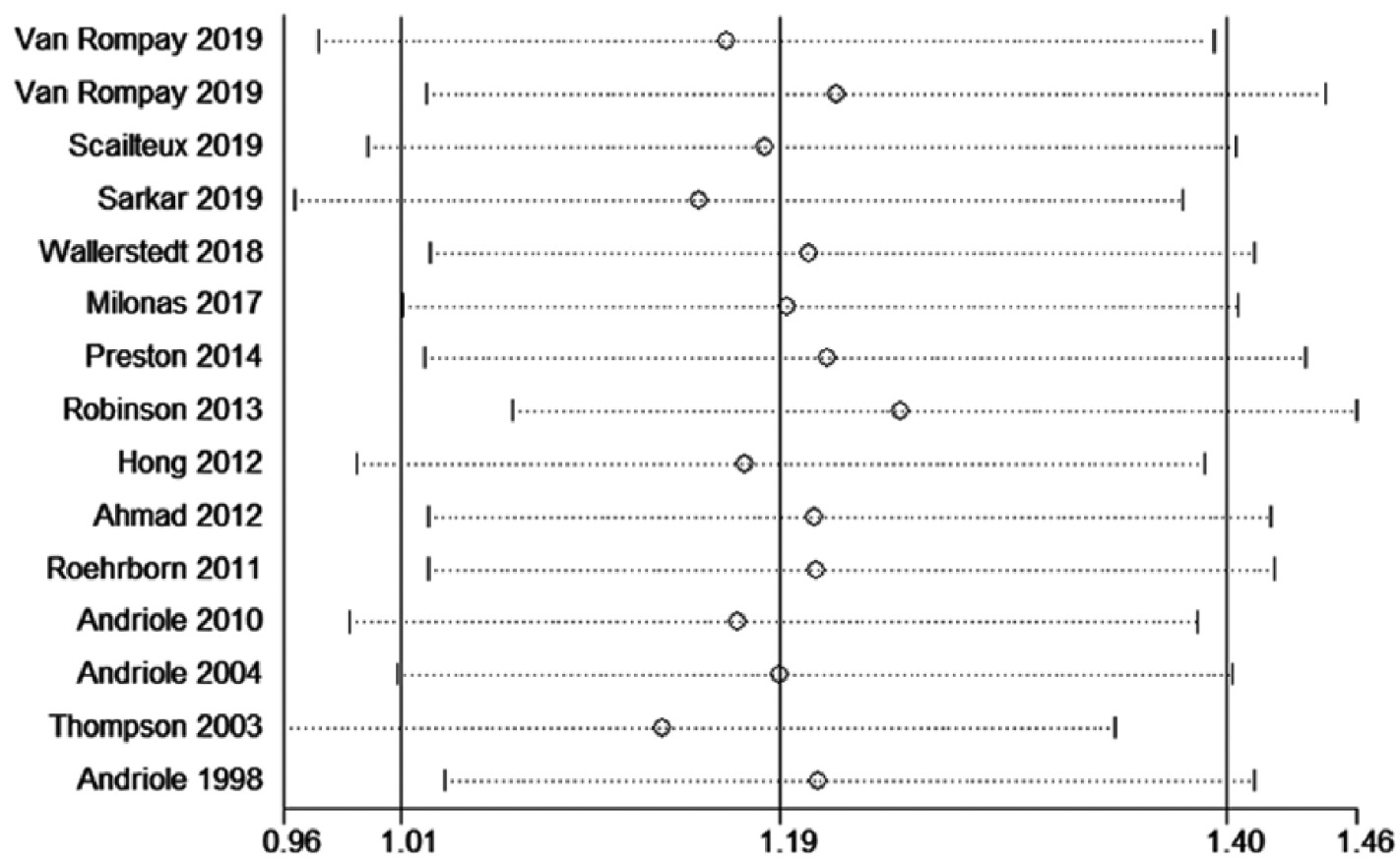

Figure 4 Sensitivity analyses for (A) overall prostate cancer; (B) Gleason 8-10 prostate cancer. 
Table 2 Meta-regression and subgroup analyses of overall and Gleason 8-10 PCa

\begin{tabular}{|c|c|c|c|c|c|c|}
\hline Variable & \multicolumn{3}{|c|}{ Overall PCa } & \multicolumn{3}{|c|}{ Gleason 8-10 PCa } \\
\hline Study design & & & 0.784 & & & 0.567 \\
\hline Cohort study & 5 & $0.72(0.52-0.99)$ & & 6 & $1.20(0.99-1.45)$ & \\
\hline Case-control & 4 & $0.85(0.74-0.99)$ & & 2 & $1.15(0.94-1.40)$ & \\
\hline Control group & & & 0.772 & & & 0.507 \\
\hline Non-5ARIs & 9 & $0.81(0.69-0.96)$ & & 8 & $1.21(1.03-1.43)$ & \\
\hline a-blockers & 2 & $0.64(0.55-0.73)$ & & 2 & $0.97(0.73-1.28)$ & \\
\hline Placebo & 6 & $0.79(0.67-0.93)$ & & 5 & $1.35(0.78-2.35)$ & \\
\hline Europe & 7 & $0.84(0.71-0.98)$ & & 5 & $1.11(0.91-1.34)$ & \\
\hline Asia & 1 & $1.24(0.66-2.32)$ & & 1 & $1.52(0.81-2.84)$ & \\
\hline Multicenter & 3 & $0.69(0.51-0.93)$ & & 3 & $1.24(0.76-2.03)$ & \\
\hline Use & & & 0.514 & & & 0.002 \\
\hline Ever-use & 7 & $0.83(0.60-1.00)$ & & 4 & $1.07(0.95-1.20)$ & \\
\hline Long-term use & 11 & $0.76(0.67-0.86)$ & & 12 & $1.35(1.13-1.61)$ & \\
\hline No. of patients & & & 0.887 & & & 0.810 \\
\hline$<5,000$ & 8 & $0.80(0.68-0.94)$ & & 7 & $1.14(0.79-1.63)$ & \\
\hline
\end{tabular}

$\mathrm{PCa}$, prostate cancer; RR, relative ratio; Cl, confidence interval; RCT, randomized controlled trial; 5-ARIs, 5-alpha reductase inhibitors; P value of random-effect meta-regression using restricted maximum likelihood (REML).

5-ARI usage and Gleason 8-10 PCa still needs to be explored. Regarding the metastatic $\mathrm{PCa}$, we did not detect a significant difference between 5-ARI and non-5-ARI users. Furthermore, in terms of survival, we found that 5-ARIs did not have a significant effect on overall survival or cancerspecific survival.

Notably, our results showed a $23 \%$ reduction in overall $\mathrm{PCa}$, which is similar to the previous report of two large scale RCT $(5,6)$. Thompson et al. also collected data on the incidence of prostate cancer among PCPT participants for an additional year, and there was a significant betweengroup difference in the rates of overall $\mathrm{PCa}(\mathrm{RR}=0.70 ; 95 \%$ CI: 0.65-0.76) (21). Recently, a retrospective 20-year cohort study, performed by Van Rompay et al., revealed that the use of 5-ARIs was associated with a lower risk of PCa diagnosis compared with a-blocker users (HR $=0.63$; 95\% CI: 0.54-
$0.73)$ and nonusers (HR $=0.61$; 95\% CI: 0.53-0.70) (8). In our subgroup analyses, we also observed similar results. We also detected a significant association between 5-ARI use and the incidence of overall PCa. A nest-control study revealed that finasteride use marginally increased the incidence of overall PCa but did not observe a similar result for dutasteride (24). A post hoc analysis of Asian men in the REDUCE study found that the incidence of prostate cancer in the dutasteride groups was lower than the placebo group (9.3\% vs. 19.6\%), but the difference was not significant $(\mathrm{P}=0.12)$ (35). For exposure time, Wallerstedt et al. found that treatment with 5-ARIs decreased the risk of overall $\mathrm{PCa}$, and the effect was larger with longer time of exposure (0.1 to 2 years: $\mathrm{HR}=0.81, \mathrm{P}=0.002 ; 2-4$ years: $\mathrm{HR}=0.39$, $\mathrm{P}<0.001 ; 4-6$ years: $\mathrm{HR}=0.40, \mathrm{P}<0.001$; and $6-8$ years: $\mathrm{HR}$ $=0.31, \mathrm{P}=0.001$ ) (18). Similarly, Robinson found that there 
was a decrease in risk with increasing duration of 5-ARI exposure for overall $\mathrm{PCa}$ combined in men receiving 5-ARI treatment for more than three years $(\mathrm{P}<0.001$ for trend) (22).

Investigating the role of 5 -ARIs in the development of high-grade PCa is an essential outcome to identify the potential harm and implications. Our results revealed that 5-ARI users had a significantly increased risk of Gleason 8-10 PCa. Meanwhile, in the different subgroups, the results were controversial, which may be due to the heterogeneity among studies. We conducted a meta-regression analysis and found that the duration of use may be the potential source of heterogeneity. Recently, a large cohort study observed that patients treated with 5-ARIs were more likely to have Gleason $8-10$ PCa $(25.2 \%$ vs. $17.0 \%$; $\mathrm{P}<0.001$ ), which is in accordance with our findings (9). The increased proportion of high-grade prostate cancer among 5-ARI users has been suggested to be related more to bias than to biology $(36,37)$. The increase in high-grade tumors seen in the previous studies may have resulted from detection bias through several mechanisms, including improved sensitivity of prostate-specific antigen testing and improved detection of small lesions of high-grade disease in the prostate after size reduction caused by 5 -ARI treatments (11,36-39). However, we cannot exclude the possibility that the increase in high-grade tumors truly does result from detection bias. It is estimated that 150-270 men would need to be treated for 7 years with finasteride to cause one addition Gleason 8-10 PCa (7), which is line with our findings that exposure time might be the source of heterogeneity. However, few studies involved the relevant patients. Hence, the actual impact of 5-ARIs on high-grade disease still needs to be explored. Concerning metastatic $\mathrm{PCa}$, we did not detect a significant between-group difference. However, likely due to the small numbers, the power of this result might be limited. The RR of metastatic $\mathrm{PCa}(1.23)$ is similar to the RR of Gleason 8-10 PCa (1.19); thus, the 5-ARIs might also be associated with an increased risk of metastatic PCa. Sarkar et al. observed that 5-ARI users are more likely to have metastatic disease (6.7\% vs. $2.9 \%$; $\mathrm{P}<0.001$ ), but they did not adjust for other variables (9). Meanwhile, Van Rompay et al. suggested that the incidence of metastatic PCa was not significantly different among 5-ARI users compared with nonusers or a-blocker users (adjusted HR: 1.12 and 0.89, respectively, $\mathrm{P}=0.54$ for both groups) (16). The studies included few metastatic disease patients, and further studies are required.

In the present study, although there was an elevated incidence of Gleason 8-10 PCa among 5-ARI users, this did not translate into an increased risk of overall death or prostate cancer death. Thus, the increased incidence of high-grade tumors is more likely due to more accurate diagnostics. It was also suggested that the decreased risk of overall PCa did not translate into improved survival, supporting the previous reports that 5-ARIs mainly affect the incidence of low-risk disease that is unlikely to progress to the lethal stage. After 18 years of follow-up for PCPT participants, there was no significant betweengroup difference in overall survival (adjusted $\mathrm{HR}=1.03$; $\mathrm{P}=0.26$ ) (21). Further, the Finnish Prostate Cancer Screening Trial observed that prediagnostic 5-ARI use was not associated with the risk of overall death or prostate cancer death (7). Stratification by amount, duration or intensity of 5-ARI use showed no survival trends. Van Rompay et al. also found that the use of 5-ARIs was not associated with a higher risk of PCa mortality regardless of comparison groups (16). However, Sarkar et al. suggested that 5 -ARI users had worse overall survival (HR $=1.10 ; \mathrm{P}<0.001)$ and cancer-specific survival $(\mathrm{HR}=1.39$; $\mathrm{P}<0.001$ ) (9), although a lead-time bias may exist and affect the survival outcomes. These results are difficult to explain because PCa is not a common cause of death in the overall population, the generality of the results is limited by the highly selected populations, and the exposure rate is low $(2,10,21)$. Few studies reported an association between 5-ARI usage and survival, and more well-conducted studies are essential.

Physicians who prescribe 5-ARIs for men with $\mathrm{BPH}$ struggle with the potentially increased risk of high-grade tumors (40). In our opinion, although 5-ARI users had potential increases in the risk of high-grade tumors, it did not translate into worse survival. These findings should provide reassurance to patients with $\mathrm{BPH}$ who are treated with these drugs. The controversies associated with this aspect lead to a general reluctance to recommend a 5-ARI chemoprevention strategies in men. Based on the evidence, 5-ARIs may not be fit for chemopreventive agents.

Our study has a number of strengths. We comprehensively searched the relevant articles and included 23 studies with a large number of cases. Therefore, this study was well powered. Furthermore, we investigated the relationship between 5-ARIs and the incidence of overall, high-grade (Gleason 8-10), metastatic PCa as well as its relationship with overall and prostate cancer-specific survival. The present study also included sensitivity analyses to identify the robustness of the final results. We also performed subgroup analyses and meta-regression based on all 
available information to explore the potential source of heterogeneity.

Of course, our study is not devoid of limitations. First, although we included a large number of studies, most studies were observational studies with inherent bias, which may have affected the final results. Next, there were differences between studies, which may have resulted in heterogeneity. Much detailed information was not available; thus, we could not perform relevant analyses, such as subgroup analysis. Some studies performed the analysis adjusted for confounders, while others may not have been adjusted, and the models adjusted for the covariates were not the same. Last, studies that involved survival outcomes were scarce, which may have limited the power of the final results and prevented evaluation of safety.

\section{Conclusions}

In conclusion, while male 5-ARI users were associated with a decreased risk of overall prostate cancer and increased risk of high-grade prostate cancer (Gleason 8-10), they were not associated with an increased risk of overall or prostate cancer mortality. 5-ARIs should be recommended carefully for use as chemopreventive agents.

\section{Acknowledgments}

Funding: None.

\section{Footnote}

Reporting Checklist: The authors have completed the PRISMA reporting checklist. Available at http://dx.doi. org/10.21037/tau-20-843

Conflicts of Interest: All authors have completed the ICMJE uniform disclosure form (available at http://dx.doi. org/10.21037/tau-20-843). The authors have no conflicts of interest to declare.

Ethical Statement: The authors are accountable for all aspects of the work in ensuring that questions related to the accuracy or integrity of any part of the work are appropriately investigated and resolved.

Open Access Statement: This is an Open Access article distributed in accordance with the Creative Commons Attribution-NonCommercial-NoDerivs 4.0 International
License (CC BY-NC-ND 4.0), which permits the noncommercial replication and distribution of the article with the strict proviso that no changes or edits are made and the original work is properly cited (including links to both the formal publication through the relevant DOI and the license). See: https://creativecommons.org/licenses/by-nc-nd/4.0/.

\section{References}

1. Bray F, Ferlay J, Soerjomataram I, et al. Global cancer statistics 2018: GLOBOCAN estimates of incidence and mortality worldwide for 36 cancers in 185 countries. CA Cancer J Clin 2018;68:394-424.

2. Preston MA, Wilson KM, Markt SC, et al. 5alphaReductase inhibitors and risk of high-grade or lethal prostate cancer. JAMA Intern Med 2014;174:1301-7.

3. Fitzpatrick JM, Schulman C, Zlotta AR, et al. Prostate cancer: a serious disease suitable for prevention. BJU Int 2009;103:864-70.

4. McConnell JD, Roehrborn CG, Bautista OM, et al. The long-term effect of doxazosin, finasteride, and combination therapy on the clinical progression of benign prostatic hyperplasia. N Engl J Med 2003;349:2387-98.

5. Thompson IM, Goodman PJ, Tangen CM, et al. The influence of finasteride on the development of prostate cancer. N Engl J Med 2003;349:215-24.

6. Andriole GL, Bostwick DG, Brawley OW, et al. Effect of dutasteride on the risk of prostate cancer. N Engl J Med 2010;362:1192-202.

7. Murtola TJ, Karppa EK, Taari K, et al. 5-Alpha reductase inhibitor use and prostate cancer survival in the Finnish Prostate Cancer Screening Trial. Int J Cancer 2016;138:2820-8.

8. Wallner LP, DiBello JR, Li BH, et al. 5-Alpha Reductase Inhibitors and the Risk of Prostate Cancer Mortality in Men Treated for Benign Prostatic Hyperplasia. Mayo Clin Proc 2016;91:1717-26.

9. Sarkar RR, Parsons JK, Bryant AK, et al. Association of Treatment With 5alpha-Reductase Inhibitors With Time to Diagnosis and Mortality in Prostate Cancer. JAMA Intern Med 2019;179:812-9.

10. Azoulay L, Eberg M, Benayoun S, et al. 5alpha-Reductase Inhibitors and the Risk of Cancer-Related Mortality in Men With Prostate Cancer. JAMA Oncol 2015;1:314-20.

11. Redman MW, Tangen CM, Goodman PJ, et al. Finasteride does not increase the risk of high-grade prostate cancer: a bias-adjusted modeling approach. Cancer Prev Res (Phila) 2008;1:174-81. 
12. Moher D, Liberati A, Tetzlaff J, et al. Preferred reporting items for systematic reviews and meta-analyses: the PRISMA statement. PLoS Med 2009;6:e1000097.

13. Higgins JP, Altman DG, Gotzsche PC, et al. The Cochrane Collaboration's tool for assessing risk of bias in randomised trials. Bmj 2011;343:d5928.

14. Higgins JP, Thompson SG, Deeks JJ, et al. Measuring inconsistency in meta-analyses. Bmj 2003;327:557-60.

15. Duval S, Tweedie R. Trim and fill: A simple funnel-plotbased method of testing and adjusting for publication bias in meta-analysis. Biometrics 2000;56:455-63.

16. Van Rompay MI, Curtis Nickel J, Ranganathan G, et al. Impact of 5 alpha-reductase inhibitor and alpha-blocker therapy for benign prostatic hyperplasia on prostate cancer incidence and mortality. BJU Int 2019;123:511-8.

17. Scailteux LM, Rioux-Leclercq N, Vincendeau S, et al. Use of 5 alpha-reductase inhibitors for benign prostate hypertrophy and risk of high grade prostate cancer: a French population-based study. BJU Int 2019;123:293-9.

18. Wallerstedt A, Strom P, Gronberg H, et al. Risk of prostate cancer in men treated with 5a-reductase inhibitors-a large population-based prospective study. J Natl Cancer Inst 2018;110:1216-21.

19. Murtola TJ, Virkku A, Talala K, et al. Outcomes of Prostate Cancer Screening by 5alpha-Reductase Inhibitor Use. J Urol 2017;198:305-9.

20. Milonas D ASSGGIJMJS. Dutasteride for the prevention of prostate cancer in men with high-grade prostatic intraepithelial neoplasia: results of a phase III randomized open-label 3-year trial. World J Urol 2017;35:721-8.

21. Thompson Jr IM, Goodman PJ, Tangen CM, et al. Long-term survival of participants in the prostate cancer prevention trial. N Engl J Med 2013;369:603-10.

22. Robinson D, Garmo H, Bill-Axelson A, et al. Use of 5alpha-reductase inhibitors for lower urinary tract symptoms and risk of prostate cancer in Swedish men: nationwide, population based case-control study. BMJ 2013;346:f3406.

23. Kjellman A, Friis S, Granath F, et al. Treatment with finasteride and prostate cancer survival. Scand J Urol 2013;47:265-71.

24. Liang JA, Sun LM, Lin MC, et al. A population-based nested case-control study in taiwan: use of 5alphareductase inhibitors did not decrease prostate cancer risk in patients with benign prostate hyperplasia. Oncologist 2012;17:986-91.

25. Hong SK, Oh JJ, Lee S, et al. Association of 5alphareductase inhibitor use and pathological features of prostate cancer in men undergoing radical prostatectomy. Prostate 2012;72:1187-92.

26. Ahmad I, Small DR, Krishna NS, et al. Prostate cancer incidence in patients on 5alpha-reductase inhibitors for lower urinary tract symptoms: A 14-year retrospective study. Br J Med Surg Urol 2012;5:179-83.

27. Roehrborn CG, Andriole GL, Wilson TH, et al. Effect of dutasteride on prostate biopsy rates and the diagnosis of prostate cancer in men with lower urinary tract symptoms and enlarged prostates in the Combination of Avodart and Tamsulosin trial. Eur Urol 2011;59:244-9.

28. Andriole GL, Roehrborn C, Schulman C, et al. Effect of dutasteride on the detection of prostate cancer in men with benign prostatic hyperplasia. Urology 2004;64:53741; discussion 542-3.

29. Irani J, Ravery V, Pariente JL, et al. Effect of nonsteroidal anti-inflammatory agents and finasteride on prostate cancer risk. J Urol 2002;168:1985-8.

30. Andriole GL, Guess HA, Epstein JI, et al. Treatment with finasteride preserves usefulness of Prostate-Specific Antigen in the detection of prostate cancer: Results of a randomized, double- blind, placebo-controlled clinical trial. Urology 1998;52:195-201.

31. Cote RJ, Skinner EC, Salem CE, et al. The effect of finasteride on the prostate gland in men with elevated serum prostate-specific antigen levels. Br J Cancer 1998;78:413-8.

32. Thomas LN, Douglas RC, Lazier CB, et al. Type 1 and type 2 5alpha-reductase expression in the development and progression of prostate cancer. Eur Urol 2008;53:244-52.

33. Niu Y, Ge R, Hu L, et al. Reduced levels of 5-alpha reductase 2 in adult prostate tissue and implications for BPH therapy. Prostate 2011;71:1317-24.

34. McConnell JD, Wilson JD, George FW, et al. Finasteride, an inhibitor of 5 alpha-reductase, suppresses prostatic dihydrotestosterone in men with benign prostatic hyperplasia. J Clin Endocrinol Metab 1992;74:505-8.

35. Akaza H, Kanetake H, Tsukamoto T, et al. Efficacy and safety of dutasteride on prostate cancer risk reduction in Asian men: the results from the REDUCE study. Jpn J Clin Oncol 2011;41:417-23.

36. Andriole GL, Humphrey PA, Serfling RJ, et al. Highgrade prostate cancer in the Prostate Cancer Prevention Trial: fact or artifact? J Natl Cancer Inst 2007;99:1355-6.

37. Goodman PJ, Thompson IM, Jr., Tangen CM, et al. The prostate cancer prevention trial: design, biases and interpretation of study results. J Urol 2006;175:2234-42.

38. Thompson IM, Chi C, Ankerst DP, et al. Effect of 
finasteride on the sensitivity of PSA for detecting prostate cancer. J Natl Cancer Inst 2006;98:1128-33.

39. Cohen YC, Liu KS, Heyden NL, et al. Detection bias due to the effect of finasteride on prostate volume: a modeling approach for analysis of the Prostate Cancer Prevention

Cite this article as: $\mathrm{Hu} \mathrm{X}$, Wang $\mathrm{YH}$, Yang ZQ, Shao YX, Yang WX, Li X. Association of 5-alpha-reductase inhibitor and prostate cancer incidence and mortality: a meta-analysis. Transl Androl Urol 2020;9(6):2519-2532. doi: 10.21037/tau-20-843
Trial. J Natl Cancer Inst 2007;99:1366-74.

40. Thompson IM, Klein EA, Lippman SM, et al. Prevention of prostate cancer with finasteride: US/European perspective. Eur Urol 2003;44:650-5. 
Supplementary

Table S1 Quality assessment according to Cochrane Collaboration Risk of Bias Tool

\begin{tabular}{|c|c|c|c|c|c|c|c|}
\hline & $\begin{array}{c}\text { Random } \\
\text { sequence generation } \\
\text { (selection bias) }\end{array}$ & $\begin{array}{c}\text { Allocation } \\
\text { concealment } \\
\text { (selection bias) }\end{array}$ & $\begin{array}{l}\text { Blinding of participants } \\
\text { and researchers } \\
\text { (performance bias) }\end{array}$ & $\begin{array}{c}\text { Blinding of } \\
\text { outcome assessment } \\
\text { (detection bias) }\end{array}$ & $\begin{array}{c}\text { Incomplete } \\
\text { outcome data } \\
\text { (attrition bias) }\end{array}$ & $\begin{array}{l}\text { Selective } \\
\text { reporting } \\
\text { (reporting bias) }\end{array}$ & $\begin{array}{l}\text { Other } \\
\text { bias }\end{array}$ \\
\hline Milonas 2017 & Low risk & Low risk & Unclear risk & Unclear risk & Low risk & Low risk & Low risk \\
\hline Thompson 2013/2003 & Low risk & Low risk & Unclear risk & Unclear risk & Low risk & Low risk & Unclear risk \\
\hline Roehrborn 2011 & Low risk & Low risk & Low risk & Low risk & Low risk & Low risk & Unclear risk \\
\hline Andriole 2010 & Low risk & Low risk & Low risk & Low risk & Low risk & Low risk & Unclear risk \\
\hline Andriole 2004 & Low risk & Low risk & Low risk & Low risk & Low risk & Low risk & Low risk \\
\hline Andriole 1998 & Low risk & Low risk & Low risk & Low risk & Low risk & Low risk & Unclear risk \\
\hline Cote 1998 & Low risk & Low risk & Unclear risk & Unclear risk & Low risk & Low risk & Unclear risk \\
\hline
\end{tabular}

